\title{
ENDPOINT ESTIMATES FOR COMMUTATORS OF SUBLINEAR OPERATORS IN THE MORREY-TYPE SPACES
}

\author{
HUA WANG
}

Abstract. Let $\left[b, \mathscr{T}_{\alpha}\right](0 \leqslant \alpha<n)$ be the commutators generated by $B M O\left(\mathbb{R}^{n}\right)$ functions and a class of sublinear operators satisfying certain size conditions. The aim of this paper is to study the endpoint estimates of these commutators on the weighted Morrey spaces and the generalized Morrey spaces, under the assumptions that $\left[b, \mathscr{T}_{\alpha}\right](0 \leqslant \alpha<n)$ satisfy (weighted or unweighted) endpoint inequalities on $\mathbb{R}^{n}$ or on bounded domains. Furthermore, as applications of our main results, we will obtain, in the endpoint case, the boundedness properties of many important operators in classical harmonic analysis on the weighted Morrey and the generalized Morrey spaces.

Mathematics subject classification (2010): 42B20, 42B25, $42 \mathrm{~B} 35$.

Keywords and phrases: Sublinear operators, weighted Morrey spaces, generalized Morrey spaces, commutators, BMO.

\section{REFERENCES}

[1] D. R. Adams, A note on Riesz potentials, Duke Math. J, 42 (1975), 765-778.

[2] F. ChiAREnZA And M. FrascA, Morrey spaces and Hardy-Littlewood maximal function, Rend. Math. Appl, 7 (1987), 273-279.

[3] D. CRUZ-URIBE AND A. FIOREnZA, Endpoint estimates and weighted norm inequalities for commutators of fractional integrals, Publ. Mat., 47 (2003), 103-131.

[4] D. CRUZ-URibe AND A. FIOREnZA, Weighted endpoint estimates for commutators of fractional integrals, Czechoslovak Math. J., 57 (132) (2007), 153-160.

[5] Y. Ding AND S. Z. LU, Higher order commutators for a class of rough operators, Ark. Mat., 37 (1999), 33-44.

[6] Y. Ding, S. Z. LU AND P. ZHANG, Weighted weak type estimates for commutators of the Marcinkiewicz integrals, Sci. China (Ser. A), 47 (2004), 83-95.

[7] J. Duonndikoetxea, Fourier Analysis, American Mathematical Society, Providence, Rhode Island, 2000.

[8] J. Garcia-Cuerva And J. L. Rubio De Francia, Weighted Norm Inequalities and Related Topics, North-Holland, Amsterdam, 1985.

[9] V. S. Guliyev, Boundedness of the maximal, potential and singular operators in the generalized Morrey spaces, J. Inequal. Appl., Article ID 503948, (2009).

[10] V. S. Guliyev, S. S. Aliyev and T. Karaman, Boundedness of a class of sublinear operators and their commutators on generalized Morrey spaces, Abstr. Appl. Anal., Article ID 356041, (2011).

[11] V. S. Guliyev, S. S. Aliyev, T. Karaman And P. S. Shukurov, Boundedness of sublinear operators and commutators on generalized Morrey spaces, Integr. Equ. Oper. Theory, 71 (2011), 327355.

[12] F. John And L. Nirenberg, On functions of bounded mean oscillation, Comm. Pure Appl. Math., 14 (1961), 415-426.

[13] R. Johnson And C. J. Neugebauer, Change of variable results for $A_{p}$ and reverse Hölder $R H_{r}$ classes, Trans. Amer. Math. Soc, 328 (1991), 639-666.

[14] Y. KOMORI AND S. SHIRAI, Weighted Morrey spaces and a singular integral operator, Math. Nachr, 282 (2009), 219-231. 
[15] L. Z. LIU AND S. Z. LU, Weighted weak type inequalities for maximal commutators of Bochner-Riesz operator, Hokkaido Math. J., 32 (2003), 85-99.

[16] Z. G. LiU AND S. Z. LU, Endpoint estimates for commutators of Calderón-Zygmund type operators, Kodai Math. J., 25 (2002), 79-88.

[17] S. Z. Lu, Four Lectures on Real H $H^{p}$ Spaces, World Scientific Publishing, River Edge, N. J., 1995.

[18] S. Z. LU, D. C. YANG AND Z. S. ZHOU, Sublinear operators with rough kernel on generalized Morrey spaces, Hokkaido Math. J., 27 (1998), 219-232.

[19] T. Mizuhara, Boundedness of some classical operators on generalized Morrey spaces, Harmonic Analysis, ICM-90 Satellite Conference Proceedings, Springer-Verlag, Tokyo, (1991), 183-189.

[20] C. B. Morrey, On the solutions of quasi-linear elliptic partial differential equations, Trans. Amer. Math. Soc., 43 (1938), 126-166.

[21] E. NAKAI, Hardy-Littlewood maximal operator, singular integral operators and Riesz potentials on generalized Morrey spaces, Math. Nachr., 166 (1994), 95-103.

[22] B. Muckenhoupt, Weighted norm inequalities for the Hardy maximal function, Trans. Amer. Math. Soc., 165 (1972), 207-226.

[23] J. PeEtre, On the theory of $\mathscr{L}_{p, \lambda}$ spaces, J. Funct. Anal., 4 (1969), 71-87.

[24] C. PÉREZ, Endpoint estimates for commutators of singular integral operators, J. Funct. Anal., 128 (1995), 163-185.

[25] C. PÉREZ AND G. PRADOLINI, Sharp weighted endpoint estimates for commutators of singular integrals, Michigan Math. J., 49 (2001), 23-37.

[26] M. M. Rao And Z. D. REN, Theory of Orlicz. Spaces, Marcel Dekker, New York, 1991.

[27] S. G. SHI, Z. W. FU AND F. Y. ZHAO, Estimates for operators on weighted Morrey spaces and their applications to nondivergence elliptic equations, J. Inequal. Appl., 2013:390 (2013).

[28] F. SORIA AND G. WEISS, A remark on singular integrals and power weights, Indiana Univ. Math. J., 43 (1994), 187-204.

[29] E. M. SteIn, Singular Integrals and Differentiability Properties of Functions, Princeton Univ. Press, Princeton, New Jersey, 1970.

[30] E. M. Stein AND G. WeIS S, Introduction to Fourier Analysis on Euclidean Spaces, Princeton Univ. Press, Princeton, New Jersey, 1971.

[31] E. M. Stein, Harmonic Analysis: Real-Variable Methods, Orthogonality, and Oscillatory Integrals, Princeton Univ. Press, Princeton, New Jersey, 1993.

[32] A. Torchinsky, Real-Variable Methods in Harmonic Analysis, Academic Press, New York, 1986.

[33] K. YABUTA, Generalizations of Calderón-Zygmund operators, Studia Math., 82 (1985), 17-31.

[34] Q. Y. XUE AND Y. DING, Weighted estimates for the multilinear commutators of the Littlewood-Paley operators, Sci. China (Ser. A), 52 (2009), 1849-1868.

[35] P. ZHANG, Weighted endpoint estimates for commutators of Marcinkiewicz integrals, Acta Math. Sinica (Engl. Ser), 26 (2010), 1709-1722.

[36] P. ZHANG AND H. XU, Sharp weighted estimates for commutators of Calderón-Zygmund type operators, Acta Math. Sinica (Chin. Ser), 48 (2005), 625-636. 